\title{
Agriculture as Social Wellbeing System in Food Security: An Epistemological Study
}

\author{
Masudul A. Choudhury ${ }^{1,2^{*}}$, Azhar Abbas ${ }^{3}$ \\ ${ }^{1}$ Faculty of Economics, Trisakti University, Jakarta, Indonesia \\ ${ }^{2}$ Department of Shari'ah and Economics, Academy of Islamic Studies, University of Malaya, Kuala Lumpur, Malaysia \\ ${ }^{3}$ Institute of Agricultural and Resource Economics, University of Agriculture Faisalabad, Faisalabad, Pakistan \\ Email: *Masudc60@yahoo.ca
}

How to cite this paper: Choudhury, M.A. and Abbas, A. (2017) Agriculture as Social Wellbeing System in Food Security: An Epistemological Study. Theoretical Economics Letters, 7, 429-447. https://doi.org/10.4236/tel.2017.73032

Received: October 27, 2016

Accepted: April 4, 2017

Published: April 7, 2017

Copyright $\odot 2017$ by authors and Scientific Research Publishing Inc. This work is licensed under the Creative Commons Attribution International License (CC BY 4.0).

http://creativecommons.org/licenses/by/4.0/

(c) (i) Open Access

\begin{abstract}
The theme of agriculture as system though it is commonly understood is an innovative area of research and erudition. It involves both a technical meaning of system and cybernetic as these arise in respect of their epistemological meaning of unity of knowledge in highly complementary orders; as well as some of the wellbeing implications are studied in methodological way within the substantive context of system and cybernetic. The result then is a scientific, technical, and social development of the theme of agriculture as system for the common human good. Within this meaningful connotation, the economics of agriculture is invoked. This area is further extended to the broader field of ecology, resource, and environment inter-causal linkages within and between them. The treatment of agriculture as system and cybernetic study then leads into methodological and mathematical formalism that can be formulated as a model of evaluation of wellbeing subject to simulacra of multidimensional variable interrelationship. With data searched by the researchers in further studies in this area of agriculture system, the wellbeing simulation subject to circular causation between the multidimensional variables can be empirically evaluated using sophisticated statistical programs. Resulting policy and inter-system results can be analyzed to derive socioeconomic inferences. A plethora of further technical studies with the methodological features of system and cybernetic study can be derived.
\end{abstract}

\section{Keywords}

System Study, Food Security, Epistemological Modelling

\section{Background of Conceptualization: System and Cybernetic Study of Agriculture}

Two concepts are brought together in this paper to present a remarkably original 
idea of studying, teaching, and researching the field of agriculture, resources, environment, and ecology in the framework of system and cybernetic study. The focus of this paper in this respect is on agriculture, as this human activity can be seen to be an important example of system science in sustainable development for human wellbeing at large. In this study a particular mention is made to an epistemological approach in the study of agriculture in relation to the social sustainability of development [1]. Thereby, the methodological approach of this study is based on the episteme of unity of knowledge.

The field of unity of knowledge in socio-scientific study invokes inquiry regarding an epistemological approach that explains how the study of agriculture can be formalized to investigate the dynamics of the intra-system and inter-system interactive, integration, and evolutionary (IIE) properties of agriculture as an analytical system. Thereby, the study of agriculture in terms of methodological development dynamics occupies the field of socio-scientific system and cybernetic study. The nature of all these interrelated fields of study is shown to represent evolutionary learning by means of inter-variable intrinsic complementarities. The dynamics leading to the study of such complementarities form the inter-causal phenomenology of social decision-making, institutionalism, and the inherent nature of the physical domain of agriculture as system. The resulting imminent methodological approach takes a mathematical overview.

The resulting methodological approach in our study results in the study of a general system as it is governed by its worldview of systemic unity of knowledge as the episteme that combines abstraction and conception of system science with its applications in social experience. Such a comprehensive understanding of phenomenology in system and cybernetic science becomes one of being and becoming of mind and matter unified in inter-causal relations between systemic verities.

The focus of study in this paper is on the general epistemology of unity of knowledge. Such a generalized methodological approach is then applied to the particular system and cybernetic study of agriculture. Foucault $[2]^{1}$ defined the meaning of episteme in this concept of the totality of realizing knowledge out of the total learning process existing in continuity of being and becoming. Also, note the model of social becoming given by Sztompka [3] along epistemic lines. This paper applies these ideas procedurally to the analytic study of agriculture as a socio-scientific system. Yet the substantive methodological approach in unity of knowledge makes a wide difference.

The second focus of this paper is on the above-mentioned epistemic methodological approach carried out in the field of agriculture as a particular system embedded in the generalized theory of socio-scientific system. The emergent ${ }^{1}$ Foucault (see Sheridan,1972, p. 191) [2] defines the word episteme as follows: "By episteme we mean... the total set of relations that unite, at a given period, the discursive practices that give rise to epistemological figures, sciences, and possibly formalized systems... The episteme is not a form of knowledge (connaissance) or type of rationality which, crossing the boundaries of the most varied sciences, manifests the sovereign unity of a subject, a spirit, or a period; it is the totality of relations that can be discovered, for a given period, between the sciences when one analyses them at the level of discursive regularities." 
study is then applied in a methodical way emanating from the methodological worldview. That is, the formalized model presents an interactive, integrative, and evolutionary process (IIE-learning process) of organically unified interconnection between epistemological methodology and formal methods that are conformable to the epistemological background. The result is the realization of the phenomenological study of agriculture as system. Such a knowledge-induced way of understanding the study of agriculture as system leads to the unification of knowledge in the space of agricultural details of the wider socio-scientific development comprehension underlying agricultural activities. The explanation of such a comprehensive epistemic worldview of organic unity of knowledge and its modeling is carried out analytically in respect of the particular system representation of agriculture.

Much wider applications of the methodological worldview can be made out of the general picture and its particularity, so as to establish the investigative approach in a universal socio-scientific study. That such an approach is a highly scientific one can be established from the words of the great philosopher of science of the Western World, Alfred North Whitehead [4]. In this paper, we have undertaken the systemic study of agriculture within the perspective of the universal theory of unity of knowledge as the episteme of system and cybernetic study of IIE-learning processes. An idea of such a holistic worldview is given by Wilson [5] in his theory of consilience.

\section{Objective}

The principal objective of this paper is to conceptually explain the original idea of the systemic dynamics in its generality of formalism. The generalized system theory in its epistemic nature is then applied to the potential study of agriculture as the interconnected and meaningful holism within the general theory and its particular applications. The socio-scientific demand of analytical investigation and explanation is thereby legitimated by the continuous interrelationship of the following type across recursive $(\Leftrightarrow)$ evolutionary learning processes:

Methodology $\Leftrightarrow$ Method $\Leftrightarrow$ Inference $\Leftrightarrow$ Continuum of IIE-learning processes in the light of consilience

Agriculture is introduced as a particular study of unified learning system of human activity in the wider epistemic sense. We specifically invoke a model of food security as a wellbeing objective criterion of organized agricultural activities [6]. We define the objective criterion of food security as a principal goal of socio-scientific future emanating from agriculture treated as a multidimensional and multivariate system of activities, and that explains circular causation interrelations (organismic) between the critical variables in IIE-learning processes. Such learning processes maintain balance of complementarities between the selected variables. The criterion function of food security studies the dynamics of agricultural sustainability [7] [8]. Such an objective criterion function of agriculture in a generalized system study also conveys the meaning of wellbeing. It invokes the analytical study of agriculture as a socio-scientific holism in system 
and cybernetic perspectives [9].

This paper is the first part of a two-part excursion in concept and empirical applications. This Part I of the research work covers the abstraction and formalism in the building bloc of the epistemic methodology underlying agriculture as an IIE-learning system and cybernetic study. The resulting formal model is derived as a general one that can be applied to the theme of agriculture as a particular form of epistemic learning system. The inner dynamics of the IIE-learning system are characterized by evolutionary learning equilibriums [10] across the continuum of knowledge, space, and time. The particular agricultural application of the generalized epistemic methodology of unity of knowledge is centered on the objective of evaluation of food security as the wellbeing criterion function. It formalizes the circular inter-causality between the selected variables of food security as a social wellbeing contract [11].

\section{Methodological Formalism: Epistemic Generality Applied to Food Security and Agricultural Wellbeing Criterion as Particulars}

We now proceed on by noting the generalized functional relationship of inter-causality between the selected variables of the wellbeing function in reference to the meaning of the following words of the great philosopher of science, Alfred North Whitehead ${ }^{2}$ [4]:

"The notion of a universal is of that which can enter into the description of many particulars; whereas the notion of a particular is that it is described by universals, and does not itself enter into the description of any other particular.”

This paper is in several sections that are embedded in the text. Section 1 gives a brief review of the literature. Section 2 formalizes the general epistemic model of unity of knowledge in terms of the inter-causal relations between the selected variables. Section 3 specifies the general model of Section 2 to the case of agriculture as system. This section formalizes the model that is imminent in respect of formalizing agriculture as system and cybernetic study. Section 4 points out the nature of inferences that is expected to arise from the analysis in Section 3. A particular empirical example is provided. Section 5 is the conclusion leading to the projected second paper on empirical work to arise in the future from the present first paper.

\section{Review of the Literature}

The epistemological study of environment and agriculture as systems; and within these of their relationship with health and disease, is of a recent academic inquiry. The paper by Osrio, Lobato, and Del Castillo [12] points out the importance of the epistemological study of natural phenomena in their words: "This area has become a scientific possibility for transcending reductionist analyses of 
classical sciences, by means of systemic comprehension of contemporary phenomena within the economic, social, environmental, political and ecological domains. However, the literature shows few specific references to an epistemological approach that may establish the boundaries for a metatheoretical structure on which knowledge can be generated in the framework of this emerging scientific discipline."

Then there is the model of input-output analysis applied to agricultural activity of the national economy. This approach was formalized by Harrison-Mayfield [13] and Midmore [14]. The importance of this study lies on understanding the formal model and applying it to the interactive relations that can be explained between the agriculture sector and the other sectors of the national economy; and within the agricultural sector as well. The study of intra-systemic relational causality and inter-systemic recursive relations can thereby be studied over time.

Furthermore, in the study of dynamic coefficients type input-output model [15] the topic of agriculture can be studied in showing the strong interaction [16] caused by agriculture and which dynamic input-output coefficients can explain in terms of the pervasiveness and continuity of inter-sectoral complementary linkages centered on agricultural activities. Global models of the international economy [17] place conceptual models of agricultural input-output tables in a global context of inter-causal relations between countries. In all, agricultural activity is brought to the forefront of a system study of interactive linkages within itself as a sector; in the national economy; and in the global economic context.

In the context of system and cybernetic approach to the study of IIE-process relations between sectors and multidimensional variables we refer here to several kinds of methods that have been used. According to the methodological explanation in this paper, the generalized epistemic model of unity of knowledge framing up the complementary nature of inter-sectoral linkages remains universal. Yet the methods of formalizing and analyzing the models emanating from the generalized methodology may be diverse, but yet maintaining conformity to the universal epistemic methodology.

The nature of system and cybernetic study of agricultural activities makes all problems examined institutionally and socially as complex analytical investigations. We consider for instance, two other areas that have recently emerged in the complexity, cybernetic and system theory of organizational behaviour reflecting the methodological study of the organization of agriculture as system [18]. Agriculture as system attenuating to its management and national economic and socially synergistic relations can be considered as an organization/ institution.

Jackson [19] and Luhmann [20] use Habermas' hermeneutics theory to explain complex behaviour and preference formation in complex organizations. Yet the idea of complexity may be based on conflicts that characterize organizational behaviour in decision-making. All such forces impinging on organizational behaviour become of the endogenous type and are characterized by di- 
verse methodical models copying the epistemic methodology. Yet the imminent system-oriented relations can be either of the nature of organic unity or of dialectical differentiation.

Agricultural system is a prime source or foundation of food system that, in return, encompasses the ways and options by which people organize them for the production, distribution and consumption of their food [21] [22]. In many ways food system is synonymous to agriculture system. As a consequence, access to adequate stock of food, and its availability and utilization are indicative of both food security and wellbeing of the agricultural system by providing health and nutritional value for human consumption and for generating farm incomes, employment and sustained living for rural inhabitants [23] [24]. As food security is linked with fulfilment of multifaceted goals, it is dependent on many socioeconomic and physical processes, agricultural in particular. Ensuring food security at mass level is achievable through effective interactions between various processes and variables that link both food production and food supply chains to adequately address issues related to the demand for food and food availability from farm to fork.

In respect of the analytical design of system modeling, Jackson [19] writes regarding the endogenous nature of interrelations between different kinds of system participants and their representative variables, parameters, and rules. It is reasonable to suggest that, there are two aspects in problem context which might have a particularly important effect on the character of the problems found intra-system. These two aspects comprise the spatial nature of the system $(s)$ denoted by $(\{\boldsymbol{x}\})$, in which the problems are located. Then there is the conscious nature of relationship between the participants denoted by parameters, $(\{\theta\})$. The bold symbols denote vectors, matrices, tensors, etc. of mathematical categories. Thus, there are two variables characterizing an evolutionary event at any point of time, $\{\theta, x(\theta)\}$. As these events change in character by variations in $\{\theta\}$, the inter-variables experience qualitative changes as well. Besides, in the generalized system model with events evaluated intertemporally, we can denote the complex system of events $(E)$ occurring in knowledge, space, and time by $E(\theta)=E(\theta, \boldsymbol{x}, t)[\theta]$.

Problems of system theory of organization arise in a hermeneutic context by the permissible nature of interaction between Jackson's delineation of unitary systems, pluralistic systems, and coercive systems. Now take the case of an agricultural strategy that includes sub-systems as represented by participatory behaviours in the event space of $E(\theta)$ and their characterizing variables. For instance, such variables can denote nutritional and agricultural food value [25], farm income, prices of farm produce, social distribution of subsidy and cost in farm production, and family income support, agribusiness financing variables, public policy on agriculture and national development planning [26]. Such variables are desired to generate sectoral linkages with agriculture. Then there is also the role of ICTs in disseminating national awareness in developing sustainability of sectoral linkages [27]. 
The resulting wellbeing function representing food security comprises the above-mentioned variables. This objective function either as social wellbeing or food security relating to agriculture studied as system could be of the type of a conventional linear separable function. In this case, the three kinds of systems, namely agricultural sector, national economy, social policies, and the role of ICTs to raise awareness on food security and its multidimensional components, remain mutually independent [28]. Consequently, no IIE-learning transformation is possible in inter-relating every one of the sub-systems (variables) to the rest of the other sub-systems (variables). The resulting model then is one of non-interaction and non-learning. An example is the linear utilitarian objective function of economic development.

Yet such genre of linear models of independently distributed variables is untenable for studying sustainability of attaining wellbeing over the continuum of knowledge, space and time dimensions. Such models cannot therefore explain the wellbeing of the agricultural sector vis-à-vis national development planning and social perspectives in favour of the multivariate IIE-learning process-oriented objective criterion function of food security with variables of food nutritional value, economic and social value, and innovation via ICTs as endogenously interrelated variables driven by the episteme of organic unity of knowledge and knowledge-induced entities (i.e. complementarities).

Shakun's [29] mathematical characterization of complex system behaviour delineates nodal linkages in continuous processes of simulacra. Any of the abovementioned sub-systemicsectoral approaches for attaining wellbeing objective (i.e. inter-variable pervasive complementarities) can be introduced into Shakun's system and cybernetic methodology of interactive organizational/institutional behaviour. Consequently, the mathematical delineation of complex systemic behaviour interconnecting nodes of decision-making, forms models of the type of Habermas' hermeneutics and organizational theory. These are construed now for the study of agricultural as system.

Soros [30] in his reflexivity theory of complex behaviour in economics, finance and institutions, criticizes the one-directional forward-oriented system of simulations. These kinds of systems have no reflexive examination in terms of history and thus recursive learning. Reflexivity is of course a most innovative and indispensable factor of learning for guiding complex interrelations and futures. But reflexivity must be in reference to a premise given as the methodological groundwork. Integrative decision-making in pluralistic systems of any of the above-mentioned systemic type requires an ethical preceptor to announce termination of an infinite game and to cause unification.

In the case of coercive systems, reflexivity relates back experience in economic, financial and institutional relations to a hegemonic methodological idea, as noted in the case of the Communism Cooperative Farms, the Capitalist globalization and national development planning, Eurocentricity and Pax Americana governance with cultural overtones. Such hegemonic consequences can also characterize the norm of a feudal agricultural society. In the case of unitary systems, 
the methodological premise of consensus (integration) among participants is important to actualize. From the lessons of reflexivity in history and social and economic systems one can discover distinct patterns of social change as pointed out by Soros.

In the history of social and economic theory, Herbert Simon's [31] organizational theory of satisficing decision-making assumes three phases at the organizational level. The first phase comprises the intelligence activity. This accounts for setting up the favorable conditions for decision-making. The second phase comprises the design activity. This accounts for searching, discovering, and analyzing possible sets of ways and means of interacting with the design activity. The third phase, called the choice stage comprises selection and implementation indetermining particular choices of actions that have been discovered and analyzed at the stage of design activity.

A hierarchical preference formation then enters the welfare (contrast this concept with wellbeing) criterion function of the organization. The maximization behaviour along with the competing preferences of individual members makes the preferences to be those of self-centered individuals (institutions/organizations). Such individualistic preferences are then moulded in ways unknown to form social preferences. Whether it is the maximization or the simulation or the satisficing nature of the criterion function, the organization selects its strategies. It thus has a perspective of the relationships governing socioeconomic variables $(\boldsymbol{x})$ and policy/strategic variables $(P)$. Here too, the behavioural factor in preference formation is critical. If the decision-making preferences are epistemologically derived from hedonism, then the methodology of individualism governing individuals, institutions, organizational behaviour and markets, prevails. The selection of the market variables will then show relationship between the resulting forms of markets by way of the marginalisttrade-offs that remain central in mainstream economic and social theory.

Underlying such a perspective of mainstream socioeconomics there is the pervasive idea of allocation of scarce resources between competing ends. This axiom stems from the neoclassical economic roots. It underlies the principle of marginal rate of substitution and opportunity cost of resources, as between agriculture and industry as competing sectors. Marginalism is the basis of the governing principle of competition linked with the axiom of resource scarcity, and thereby, with methodological individualism and independence between competing agents and competing alternatives.

Agricultural organizational behaviour by way of social, economic, and traditional reflexivity of a feudal society can also imitate the model of methodological individualism. Thereby, the holistic model of the IIE-process learning type, so much required for studying transformation and sustainability of a balanced national development planning with agriculture inter-linked with the other sectors as a holistic system, cannot be studied. Such a kind of competing and methodological individualistic model of agricultural activities in the national economy is found to center on today's national development planning and the behaviour of 
farmers in their small farm holdings that fail to organize into entrepreneurial cooperatives.

The failure of organizational theory, institutionalism, and thereby social holistic responsibility in terms of epistemic unity of economic theory leads to the study of the worldview of unity of knowledge and what it has to offer as a scientific revolution vis-à-vis socioeconomic governance. An example is that of agriculture as a system of diverse interrelations exemplified by the dynamics of inter-variable relational complementarities in the wellbeing objective function comprising nutritional and agricultural food value [22], economic and social variables, policy variables, and the role of ICTs in raising information and conscious response among all.

Since the scientific nature of the episteme of unity of knowledge cannot be found in all of mainstream economic theory [32], therefore the episteme of unity of knowledge as axiom must be sought for in some other methodological premise. In the history of all of science and analytic thought, the dynamics of unity of knowledge can only be found in the deeply scientific understanding of the moral and ethical episteme. In such a foundational premise, agricultural, ecological, and environment are studied as being centered in the sustainability of exchange in the good things of life for attaining the wellbeing objective of inter-variable complementarities as sign of relational balance.

That is, pervasive complementarities signify the meaning of inter-causal balance between the good choices of life. Thereby, two equivalent meanings of moral unity of being and becoming underlying the episteme of unity of knowledge and the world-system are articulated, formalized, applied and continued in perpetuity to form what we call as the total learning process in unity of knowledge and its induction of the world-system (e.g. agriculture as knowledge-induced system). The formal articulation, application, and continuity of this unique and singular precept of organic unity comprise the foundational ontology of moral belief. It powerfully constructs the generalized world-system according to the axiom, nature, and structure of such organic unity. It is most effectively carried forward by the monotheistic law impacting upon the world-system. The example here is of the agricultural sector. It carries along with its IIE-learning processes across sectors of the national development planning the theme of organizational behaviour and institutionalism at the grassroots spreading all over in system linkages by relational holism with the entirety of agricultural activities. Such was the understanding of concepts of jus divinum and jus pretium linked with the agricultural holism in Physiocratic economic thought [33].

By applying this topography of knowledge induction in participatory behaviour all consequential results become dynamic in nature in terms of knowledge-flows. Preference-dynamics, institutional and organizational preference formation, moral and socioeconomic sustainability of the discursive IIE-learning processes, take the form of evolutionary epistemology. The imminent result is a continuum of events denoted by $E\{\theta, \boldsymbol{x}(\theta), t(\theta)\}$ evolved by circular causation relations between the variables being charted across events. Every one of 
such events characterizes IIE-learning systems.

\section{The Nature of Economic Organization According to the Episteme of Unity of Knowledge: General System Question}

The discursive behaviour of participants, their preferences, and the representative variables taken in and across interacting, integrating, and evolutionary learning systems, establish sustainability by virtue of continuous organic learning between vector-designated events $E\{\theta, \boldsymbol{x}(\theta), t(\theta)\}$ in terms of unity of knowledge between the learning entities.

The statistically estimated system is firstly evaluated in terms of the given data. This stage yields the results in respect of the existing state of the issue and problem under study. Next the estimated system is simulated with a given normative view. The reconstruction results characterize the level of consciousness of agents, the changed nature of programs, instruments, policies and regulations along with the simulated socio-scientific variables. These two steps of evaluation together comprise estimated and simulated $x(\theta)$-variables. The evolution of learning $(\theta)$, inducing all the variables and agent-specific participation and dynamic consensual preferences, comprises the functional ontology, that is engineering ontology [34]. These formulate the algorithms of the IIE-learning system in analytical forms.

The evaluation of the degree of systemic unity gained by this sequence of reconstruction is done by simulating a wellbeing criterion function, say $W(\theta, \boldsymbol{x}(\theta))$, subject to the series of circular causation relations between the $\{\theta, \boldsymbol{x}(\theta), t(\theta)\}$-variables. The process of simulation continues in perpetuity by way of revisions in the $\{\theta, \boldsymbol{x}(\theta), t(\theta)\}$ vector of variables over evolutionary processes involving re-simulations of the same type of models over time. Simulations of $W(\theta, \boldsymbol{x}(\theta), t(\theta))$, subject to circular causation relations as processes, and occurring between the vector of variables, $\{\theta, \boldsymbol{x}(\theta), t(\theta)\}$-values provide the total phenomenological reality combining the knowledge induction and its explained impact on the variables that characterize the world-system (e.g. agriculture as system).

\section{Conceptualizing the Model of Unity of Knowledge for Agriculture as System}

\subsection{Vectors of Variables [35]}

(1) "health value" variables of food, $\left(h_{1}, h_{2}, \cdots, h_{N 1}\right)$ : The variables of this vector are selected from the consumer's side in terms of the intake of kinds of required nutrients and consumption of agricultural sources for the intake of health value; and also from the supply side in terms of the sources traced to the supply of specific nutrients in agricultural sources of food, fruits, vegetables, milk, and livestock. An important potential but problematic source of health value of food is found in milk. But the small farm size together with low farm-prices as opposed to dealer's mark-up price of milk, make the production of milk uncompetitive for small scale farmers. There are no effective cooperatives among farmers 
to raise the competitive edge of milk production. Consequently, the health value of milk cannot be enhanced. In the vector of health-value variables will be included cost of providing traced out appropriate inputs of nutrient and health value sources in milk; cost of attaining projected policy goals as pointed out in footnote 5; and the cost of improving the health and nutritional value of milk provided by small scale farmers. All these details become the variables of the health and nutrient vector.

(2) "nutritional value" variables of food, $\left(n_{1}, n_{2}, \cdots, n_{N 2}\right)$ : Likewise, in this case as above the sources of demand and supply of health value of agricultural food are considered. The additional variables of the vector of variables in (1) will be included.

(3) economic variables: value added in agriculture $\left(x_{1}\right)$, investment (financing) $\left(x_{2}\right)$, employment $\left(x_{3}\right)$, price level $\left(x_{4}\right)$, consumption per capita $\left(x_{5}\right)$, arable acreage under agricultural $\left(x_{6}\right)$, cost of crop insurance to maintain and improve the related stock of livestock that feed on crop $\left(x_{8}\right)$. Such relationships between crop insurance and crop sustainability warrant the supply of good nutritional and health value of agricultural food. The economic vector thus interactively integrates with vectors (1), (2), and (3). Also included in the vector will be transportation cost $\left(x_{7}\right)$, and preservation cost $\left(x_{8}\right)$.

(4) social variables: generating innovation out of ICTs by using the cost of servicing by ICTs $\left(y_{1}\right)$ to disseminate awareness and knowledge of nutritional, health value, while understanding the economic effects of realizing the various sources of benefits from the awareness of the vectors (1)-(3), which is crucial as a social contribution. There is also the variable denoting household education $\left(y_{2}\right)$ with its attenuating expenditure allayed in the public and private sector contributions to realize the benefits of vectors (1)-(4).

Finally, in vector (4) ordinal parameters are constructed for evaluating balance of circular causal relationship between the variable for establishing food security function. This empirical stage enables the evaluation of the quantitative version of the equivalent wellbeing index, which indicates the inter-causal balance of relationship between the mentioned variables in the various vectors. These parameters are denoted by $\{\theta)^{3}$. They signify an attained level of wellbeing numerically estimated as estimated degrees of balance between the inter-variable relations that are attainable with simulation between the variables in the various vectors. Computation of the underlying $\{\theta\}$-parameters is explained in footnote 3 .

The above selection of multivariate vectors shows that, food security when explained by the wellbeing concept of organic relationship occurring by interaction between the variables proves to be an important study in sustainable development.

${ }^{3}$ Say $\theta^{\star}$ has a value 10 assigned to the best vector variable value (say $x^{\star}$ ) under a column of variable values for any given vector. The assignment of all other column-specific variable values (denoted by " $P$ ") is computed by $\theta_{I}=x_{i} \cdot\left(\theta^{*} / x^{*}\right)$. Each column parameter values are thus constructed. The final column of $\theta_{j}$-values are averages of $\left\{\theta_{l}\right\}$-values of all ith columns (say " $n$ "). Thus,

$\left\{\theta_{\text {avg }}\right\}=\sum_{i=1}^{n}\left\{\theta_{I}\right\} / n$. 
In the model formulation we start by the expression (1) of primal ontology to further lead to the explanation of the epistemological groundwork.

The expression,

$$
\left(\Omega \rightarrow_{S} \approx(\Omega, S)\right)
$$

is used to convey the meaning that the knowledge domain invokes the understanding of the episteme of unity of knowledge in the scheme and order of all things. $\Omega$, the ontological base, is unravelled incrementally by the mapping " $S$ " as evolutionary ontology. " $S$ " being the primal transmission medium of extracting knowledge from the super-cardinal super-space of knowledge " $\Omega$ " [36] has its evolutionary equilibriums that are attained within evolutionary neighbourhoods that remain mathematically open and non-compactly premised in evolutionary learning space [37].

A discursive function, say $E(\cdot)$ extracts knowledge from the primal ontology of $\left(\Omega \rightarrow_{S} \approx(\Omega, S)\right)$. Thereby, $E\left[\left(\Omega \rightarrow_{S} \approx(\Omega, S)\right)\right]$ enjoins the total premise of the evolutionary epistemology. This is now denoted by

$\{\theta\} \in E\left[\left(\Omega \rightarrow_{S} \approx(\Omega, S)\right)\right]$, and by every monotonic positive functional mapping of this primal ontology and the discursive medium of the participants in deriving knowledge-flows, $\{\theta\}$. The integrated combination of these three primal components of the interactively integrated premise forms the basis of good choices. These are denoted by (MQS).

We therefore write,

$$
\{\theta\} \approx \operatorname{MQS} \in E\left[\left(\Omega \rightarrow_{S} \approx(\Omega, S)\right)\right]
$$

$\{\theta\}$ as derived knowledge from the ontological origin directs abstraction, empirical applications and experience. These $\theta$-embedded socioeconomic and policy variables are denoted by $\{\boldsymbol{x}(\theta)\}$. We thereby write by applying the functional ontology denoted by $\{f(\cdot)\}$ (Rucker, 1982),

$$
f\{\theta\} \approx\{x(\theta)\} \approx \mathrm{MQS} \in E\left[\left(\Omega \rightarrow_{S} \approx(\Omega, S)\right)\right]
$$

Thereby, $\{\theta\}$ and $f\{\theta\}$ form the domain of

$$
\left\{\theta, \boldsymbol{x}(\theta) ; \operatorname{MQS} \in E\left[\left(\Omega \rightarrow_{S} \approx(\Omega, S)\right)\right]\right\},
$$

Finally, by the mathematical union and intersection of expressions (2) and (3) as extendible domains of knowledge and knowledge transformations towards actualizing evolutionary knowledge domains, we derive the result,

$$
\{f\{\theta\},\{x(\theta)\}\} \approx \text { MQS } \in E\left[\left(\Omega \rightarrow_{S} \approx(\Omega, S)\right)\right]
$$

A special case of expression (5) is the following one along with all monotonic positive transformations of the same:

$$
\{\theta, x(\theta)\} \approx \operatorname{MQS} \in E\left[\left(\Omega \rightarrow_{S} \approx(\Omega, S)\right)\right]
$$

The above sequence of expressions brings out the following result:

The primal ontology is continuously recalled to commence the epistemic learning processes at junctures of evolutionary learning events that are evaluated at stations of events. Such continuums of events are evaluated by estimating and 
simulating the quantitative form of the wellbeing function (e.g. food security function) in reference to the system of circular causal relations between the variables of the vector, $\{\theta, x(\theta), t(\theta)\}$. Such reinforcing continuums of unity of knowledge establish the meaning of sustainability. The properties of this attribute of sustainability are derived from the mathematical continuity properties of expressions (1)-(6).

\subsection{Particular Model of Epistemic Unity of Knowledge for Agriculture as System and Cybernetic Study}

Mathematical model of agricultural activities as a system and cybernetic study of inter-causal relationship between the selected variables that define the wellbeing function as an expression of balance of complementarities between the inter-variable relations as mentioned earlier, is formalized as follows:

We define the following variables:

$$
\boldsymbol{x}(\theta)=\{x 1, x 2, x 3, x 4, x 5, x 6, y, p 1, p 2, p 3, p 4, p 5\}[\theta],
$$

$[\theta]$ outside the bracket means induction of each and all of the variables within $\{.$.$\} .$

$x 1$ : quantity of farm labor employed in the farming cooperative enterprises;

$x 2$ : quantity of capital employed complementary to $x 1$ in the organization of farming enterprise;

$x 3$ : output of the agricultural sector;

$x 4$ : profits earned in agricultural activities in view of the dynamic basic needs and participatory nature of the farming enterprises as a networked organization;

$x 5$ : stakeholders' wealth earned by enhancement of productive activities in agricultural activities with its inter-sectoral link in the national development planning;

$x 6$ : value of agricultural natural resources available for sharing in the agricultural sector between capital, labor, and shareholders;

$y$ : agricultural development financing;

$p 1$ : number (or ratio) of agricultural enterprises playing their inter-sectoral role in widening sectoral and project interconnection;

$p 2$ : human resource development in physical and expenditure terms;

$n$ : The nutritional and agricultural food value vector was defined earlier;

ICT-variables are indigenous technological sources for spreading awareness of the agricultural wellbeing (food security) as a system described by the balance of interrelations between the endogenous variables.

The epistemic unity of knowledge is signified by the unifying interaction in the form of participation and complementarities between all the named variables in the vectors. The functional form of " $\theta$ " in terms of all the explanatory variables of participatory relationship as balance, that epistemologically underlies the episteme of unity of knowledge in reference to the methodological foundation of understanding agriculture as system. The functional form conforms with an demerges from the general model of wellbeing. The functional form of " $\theta$ " in terms of all the assigned variables is evaluated as the quantitative measure of the 
wellbeing function of food security as a multidimensional function of the variables. " $\theta$ " as functional relationship denoting wellbeing, undergoes empirical evaluation. Evaluation is done firstly, as "estimation", and secondly, as "simulation" of the estimators. Simulation implies policy changes that can be enacted by suitably altering the coefficients of the evaluated system of circular causation between the inter-variable relations. Besides, the endogenous relations of the inter-causal variables are induced by the " $\theta$ "-parameter, such that each of such variables is related functionally to the rest of the variables in the vector.

The social wellbeing equivalence of food security function is a multivariate function of nutritional and agricultural food value along with economic and social variables and the technological induction of ICTs. The expression for the wellbeing function is as follows:

Evaluate

$$
W(x(\theta))
$$

Subject to,

$$
\begin{gathered}
z_{i}=f_{i}^{\prime}\left(\theta, \mathbf{z}_{i}^{\prime}\right)[\theta], i \neq i^{\prime}=1,2, \cdots, 14 \\
\theta=f(z(\theta))
\end{gathered}
$$

We can further write the forms of the equations in the log-linear transformation out of the following expressions:

$$
\begin{gathered}
W(x(\theta))=A(\theta) \cdot \prod_{i} x_{i}^{a i} \\
x_{i}=A_{i}(\theta) \cdot \prod_{i^{\prime}} x_{i^{\prime}}^{a i^{\prime}} \\
\theta=B(\theta) \cdot \prod_{i} x_{i}^{\prime a i}
\end{gathered}
$$

$i, j=, 1,2, \cdots, n$ say; $i \neq j$

The parametric $\theta$-values are thereby assigned by a combination of two integral experiences: Firstly, an algorithmic computation is done in respect of the column of $\mathbf{z}(\theta)$-values. Secondly, algorithmic values are checked and revised against the results of collegial expert discourse supported by primary data results.

\subsection{Example of Financial Trust and Endowment in Contributing to Agriculture as Socio-Ethical System}

An example of the type of model of social development of agriculture as system for attaining social wellbeing is explained by Jaiyeoba H. B, Ndzembanteh A. N. Ibrahim, T. Yousuf H.M., Mory, F. S. [38] in regards to the Islamic grassroots trust and endowment financing. This prescribed method of social financing with the purpose of engaging the poor and unemployed in productive activity by utilizing assets donated by the rich and resourceful in phsyical form or cash is called "waqf". Its principal objective in agricultural development for the engagement of the underprivileged is to generate empowerment and entitlement in perpetuity by way of employment and income generation, human resource development, and alleviation of poverty at the grassroots. One of the Islamic 
financing instruments used to mobilize cash waqf into productive directions is the Islamic profit-sharing scheme called mudarabah. In this kind of financing, banks continue to finance waqf in perpetuity for the wellbeing of the grassroots recipients by mobilizing part of bank savings in profit-sharing financing schemes.

Considering the vaster perspective of agriculture as system with the focus being on wellbeing, the social extension of waqf is actualized by the interactive, integrative, and dynamic evolutionary attributes of progression in productivity, and extension and sustainabiliy of the waqf related projects linked with wider portfolio networking of social inclusive financing. Examples of such waqf and financing portfolio are projects linked with agricluture towards enabling the poor and needy. They can now progressively graduate out of being recipients of waqf benefits into economically solvent citizens.

In the waqf financing portfolio there are the financing instruments with which profit-sharing projects called mudarabah can be combined to perpetuate solvability and sustainability of waqf assets. Some such complementary financing instruments are charitable cash-financing called zakat; equity-financing called musharakah; mark-up financing by Islamic banking called murabaha; Islamic bond financing called sukuk; and a host of Islamic approved secondary financing instruments. All these are based on interest-free schemes. Besides, waqf as social assets can be networked together in the agricultural sector for attaining national wellbeing out of the agricluture sector by the use of waqf schemes.

Further examples of such agricultural schemes, which have now graduated into national and international mega-projects are Amanah Ikhtiar enterprise in Malaysia (Amanah Ikhtiar Malaysia, online) [39]; Grameen Bank in Bangladesh, online [40]); and Bangladesh Academy for Rural Development (BARD) [41].

\subsection{Exemplifying the Circular Causation Relations of a Small Scale National Economy Model}

We have left a second paper to be devoted to an empirical study of agriculture as system. But for reasons of exemplifying a small sub-sectoral economy we take the case of the energy sector of Oman in relation to other selected sectors, and the employment and financing variables. Such a circular causation system of relations was evaluated for the Sultanate of Oman by Choudhury \& Hossain [42]. The empirical study on inter-causality between the selected sectors gave the following estimated equation:

$$
\begin{aligned}
\log Q m a= & -7.017+1.359 \log Q p+\log 0.306 Q g+0.291 \log Q m i \\
t-\text { stats } & (-0.970) \quad(1.148) \quad(0.607) \quad(2.397) \\
& -0.328 Q u-0.171 \log Q c-0.002 \log Q f i n+0.401 \log E \\
& (-0.397) \quad(-0.675) \quad(-0.101)
\end{aligned}
$$

The following symbols are defined: $(m a)$ manufacturing sector, $(p)$ petroleum sector, $(g)$ gas sector, $(m i)$ minerals sector, $(u)$ utility sector, $(c)$ construction sector, $(f)$ financial sector. $E=$ total number of employed labor force.

The estimated coefficients in Table 1 give the inter-variable partial elasticity 
coefficients at their different levels of significance according to the t-statistics. Similar estimated equations could be evaluated for agriculture in inter-sectoral relations as an empirical system based on the background episteme of unity of knowledge. This premise is used methodologically in constructing the circular causation estimable equations like Equation (14). The methodical estimation of the system of equations shows the degree of inter-variable relations in respect of the inference derived from the positive signs of the coefficients of the variables signifying degrees of inter-variable complementarities. The system of inter-sectoral and inter-variable circular causation variables would then follow. Such a small system of circular causation system of inter-variable coefficients is shown in Table 1 derived from the study of selected sectoral linkages in the Sultanate of Oman.

\section{Conclusions}

The theme of system and cybernetic study applied in development economics is not a well-known field of inquiry. Yet a system and cybernetic approach in its generalized formalism involving the extended field of economic, social, and scientific study is of a deeply academic orientation. This is particularly the case with the system study of agricultural activities. The totality of agricultural activities marks the essential nature of agriculture as system studied by the interactive, integrative, and participatory development planning in dynamic evolutionary form based on an epistemic mold.

The academic investigation in this paper found that the methodology of studying system science applied to agriculture as a specific case within the national and international development planning context, must necessarily find its epistemological foundation. This paper explained that, methodological foundation

Table 1. Circular Causation Effects between the Variables.

\begin{tabular}{|c|c|c|c|c|c|c|c|}
\hline $\mathrm{Ma}$ & $\begin{array}{l}\text { P, } \\
(+),\end{array}$ & $\begin{array}{l}\text { G, } \\
(+),\end{array}$ & $\begin{array}{l}\mathrm{Mi}, \\
(+)\end{array}$ & $\begin{array}{l}\text { C, } \\
(-),\end{array}$ & $\begin{array}{l}\mathrm{U}, \\
(-),\end{array}$ & $\begin{array}{l}\mathrm{F}, \\
(-),\end{array}$ & $\begin{array}{l}\mathrm{E} \\
(+)\end{array}$ \\
\hline $\mathbf{P}$ & $\begin{array}{l}\mathrm{Ma}, \\
(+)\end{array}$ & $\begin{array}{c}\mathrm{G} \\
(-)\end{array}$ & $\begin{array}{l}\mathrm{Mi}, \\
(+)\end{array}$ & $\begin{array}{c}\text { C, } \\
(+)\end{array}$ & $\begin{array}{l}\mathrm{U} \\
(+)\end{array}$ & $\begin{array}{l}\text { F, } \\
(-),\end{array}$ & $\begin{array}{c}\mathrm{E} \\
(-)\end{array}$ \\
\hline G & $\begin{array}{l}\mathrm{Ma}, \\
(+),\end{array}$ & $\begin{array}{l}\mathrm{P}, \\
(-),\end{array}$ & $\begin{array}{l}\mathrm{Mi}, \\
(+)\end{array}$ & $\begin{array}{c}\text { C, } \\
(+)\end{array}$ & $\begin{array}{c}\mathrm{U} \\
(+)\end{array}$ & $\begin{array}{l}\text { F, } \\
(+),\end{array}$ & $\begin{array}{c}\mathrm{E} \\
(-)\end{array}$ \\
\hline $\mathbf{M i}$ & $\begin{array}{l}\mathrm{Ma}, \\
(+)\end{array}$ & $\begin{array}{l}\text { P, } \\
(+),\end{array}$ & $\begin{array}{c}\mathrm{G} \\
(+)\end{array}$ & $\begin{array}{c}\text { C, } \\
(+),\end{array}$ & $\begin{array}{c}\mathrm{U} \\
(-)\end{array}$ & $\begin{array}{l}\mathrm{F}, \\
(+),\end{array}$ & $\begin{array}{c}\text { E } \\
(+)\end{array}$ \\
\hline C & $\begin{array}{l}\mathrm{Ma}, \\
(-)\end{array}$ & $\begin{array}{l}\mathrm{P}, \\
(+),\end{array}$ & $\begin{array}{c}\mathrm{G} \\
(+)\end{array}$ & $\begin{array}{l}\mathrm{Mi} \\
(+)\end{array}$ & $\begin{array}{c}\mathrm{U} \\
(-)\end{array}$ & $\begin{array}{l}\mathrm{F}, \\
(+),\end{array}$ & $\begin{array}{c}\text { E } \\
(+)\end{array}$ \\
\hline $\mathrm{U}$ & $\begin{array}{l}\mathrm{Ma}, \\
(-),\end{array}$ & $\begin{array}{l}\text { P, } \\
(+),\end{array}$ & $\begin{array}{c}\mathrm{G}, \\
(+)\end{array}$ & $\begin{array}{l}\mathrm{Mi}, \\
(-)\end{array}$ & $\begin{array}{c}\text { C, } \\
(-),\end{array}$ & $\begin{array}{l}\text { F, } \\
(+),\end{array}$ & $\begin{array}{c}\text { E } \\
(+)\end{array}$ \\
\hline F & $\begin{array}{l}\mathrm{Ma}, \\
(-),\end{array}$ & $\begin{array}{l}\text { P, } \\
(-),\end{array}$ & $\begin{array}{c}\mathrm{G}, \\
(+),\end{array}$ & $\begin{array}{l}\mathrm{Mi}, \\
(+),\end{array}$ & $\begin{array}{c}\mathrm{C}, \\
(+),\end{array}$ & $\begin{array}{c}\mathrm{U} \\
(+)\end{array}$ & $\begin{array}{c}\mathrm{E} \\
(-)\end{array}$ \\
\hline $\mathrm{L}$ & $\begin{array}{l}\mathrm{Ma}, \\
(+),\end{array}$ & $\begin{array}{c}\mathrm{P}, \\
(-)\end{array}$ & $\begin{array}{c}\mathrm{G}, \\
(-)\end{array}$ & $\begin{array}{l}\mathrm{Mi}, \\
(+),\end{array}$ & $\begin{array}{c}\text { C, } \\
(+),\end{array}$ & $\begin{array}{c}\mathrm{U} \\
(+)\end{array}$ & $\begin{array}{c}\mathrm{F} \\
(-)\end{array}$ \\
\hline
\end{tabular}


in terms of unity of knowledge and its induction of the working of the unified world-system (agriculture). Agriculture as system and cybernetic study is one such case within the greater scope of its wellbeing orientation, i.e. food security objective.

This paper focused on the two pronged case studies. Firstly, it established a generalized system model based on the episteme of unity of knowledge to explain extensively participatory (inter-variable complementarities) theory of systems. Such a generalized epistemological approach was shown to be contrary to the dialectical and marginalist conflict-oriented system and cybernetic study that riddle the mainstream socioeconomic literature.

The details of the generalized theory of systems in terms of the episteme of unity of knowledge and the agricultural sector, both taken up in the participatory economic development thought, were brought together in this first part of the research paper. This presented a conceptual approach in the field of agriculture as a particular example of system and cybernetic study in socio-scientific research. Within such an approach the paper focused on the evaluation of the wellbeing index in the generalized meaning of systems, and the specific study of food security with nutritional and agricultural food value and the economic, social, and technological variables in the agricultural food security function as a wellbeing index. Such a perspective of agriculture as system has been noted by The Economics of Ecosystem and Biodiversity [43]. Judi W. Wakhungu of the Kenya Ministry of Environment, Natural Resources \& Regional Development (TEEB report) points out in her words the "complex interrelationship between agricultural productivity and availability of healthy biodiversity and ecosystems" in the novelty of TEEB study.

\section{References}

[1] McDermott, J., Aït-Aïssa, M., Morel, J. and Rapando N. (2013) Agriculture and Household Nutrition Security-Development Practice and Research Needs. Food Security, 5, 667-678. https://doi.org/10.1007/s12571-013-0292-6

[2] Foucault, M. (1972) The Archeology of Knowledge and the Discourse on Language. Translated by Sheridan, A.M., Harper Torchbooks, New York.

[3] Sztompka, P. (1974) Systemic Models in Functional Analysis. In: System and Function, towards a Theory of Society, Academic Press, New York, 47-57.

[4] Whitehead, A.N. (1978) Process and Reality. In: Griffin, D.R. \& Sherburne, D.W., Eds., The Free Press, New York, 7, 24, 41-42.

[5] Wilson, E.O. (1998) Consilience: Unity of Knowledge. Vantage Press, New York.

[6] Pinstrup-Andersen, P. (2009) Food Security: Definition and Measurement. Food Security, 1, 5-7. https://doi.org/10.1007/s12571-008-0002-y

[7] Webb, P. and Block, S. (2012) Support for Agriculture during Economic Transformation: Impacts on Poverty and Undernutrition. Proceedings of the National Academy of Sciences of the United States of America, 109, 12309-12314. https://doi.org/10.1073/pnas.0913334108

[8] Marler J.B. and Wallin, J.R. (2006) Human Health, the Nutritional Quality of Harvested Food and Sustainable Farming Systems. Mimeo. Nutrition Security Institute, 
Washington DC.

[9] Yolles, M. (1998) A Cybernetic Exploration of Methodological Complementarism. Kybernetes: International Journal of Systems and Cybernetics, 27, 527-542. https://doi.org/10.1108/03684929810221564

[10] Campbell, D.T. (1987) Evolutionary Epistemology. In: Radnitzky, G. and Bartley III, W.W., Eds., Evolutionary Epistemology, Rationality, and the Sociology of Knowledge, Open Court, La Salle, 47-89.

[11] Hawley, A.H. (1986) Human Ecology. The University of Chicago Press, Chicago, IL.

[12] Osrio, L.A.R., Lobato, M.O. and Del Castillo, X.A. (2009) An Epistemology for Sustainability Science: A Proposal for the Study of the Health/Disease Phenomenon. International Journal of Sustainable Development \& World Ecology, 16, 48-60. https://doi.org/10.1080/13504500902760571

[13] Harrison-Mayfield, M. (1996) Rural Economic Modeling and Multisectoral Approach. In: Midmore, P. and Harrison-Mayfield, L., Eds., Rural Economic Modeling and Input-Output Approach, CAB International, Oxford, 1-19.

[14] Midmore, P. (1996) Future Directions for Multi-Sectoral Modeling and Rural Economies. In: Midmore, P. and Harrison-Mayfield, L., Eds., Rural Economic Modelling, an Input-Output Approach, CAB International, Oxford, 99-108.

[15] Miller, R.E., Polenske, K. and Rose, A.Z., Eds. (1989) Frontiers of Input-Output Analysis. Oxford University Press, New York.

[16] Smith, T.S. (1992) Strong Interactions. University of Chicago Press, Chicago, IL.

[17] Naqvi, S.N.H. (1994) Developing Countries and the Uruguay Round Agreement. Journal of Economic Cooperation among Islamic Countries, 15, 91-112.

[18] Zezza, A. and Tasciotti, L. (2010) Urban Agriculture, Poverty, and Food Security: Empirical Evidence from a Sample of Developing Countries. Food Policy, 35, 265 273.

[19] Jackson, M.C. (1993) Systems Methodology for the Management Sciences. Plenum Press, New York.

[20] Luhmann, N. (1995) Social Systems. Translated by Bednarz Jr., J. and Baecker, D., Stanford University Press, Stanford.

[21] Malassis, L. (1994) Feed the People. Flammarion (Dominos), Paris, 126 p.

[22] Frison, E.A., Smith, I.F., Johns, T., Cherfas, J. and Eyzaguirre, P.B. (2006) Agricultural Biodiversity, Nutrition, and Health: Making a Difference to Hunger and $\mathrm{Nu}$ trition in the Developing World. Food and Nutrition Bulletin, 27, 167-179. https://doi.org/10.1177/156482650602700208

[23] Friel, S. and Baker, P.I. (2009) Equity, Food Security and Health Equity in the Asia Pacific Region. Asia Pacific Journal of Clinical Nutrition, 18, 620-632.

[24] Fanzo, J., Hunter, D., Borelli, T. and Mattei, F., Eds. (2013) Diversifying Food and Diets: Using Agricultural Biodiversity to Improve Nutrition and Health. Routledge, London.

[25] Arsenault, J.E., Hijmans, R.J. and Brown, K.H. (2015) Improving Nutrition Security through Agriculture: An Analytical Framework Based on National Food Balance Sheets to Estimate Nutritional Adequacy of Food Supplies. Food Security, 7, 693 707. https://doi.org/10.1007/s12571-015-0452-y

[26] Morris P.M., Neuhauser, L. and Campbell, C.C. (1992) Food Security in Rural America: A Study of the Availability and Costs of Food. Journal of Nutrition Education and Behavior, 24, 52S-58S.

[27] Technology Watch (2009) ICTs and Food Security. ITU-T. Technology Watch Re- 
port, Geneva, Switzerland.

[28] Mahmood, Z., Iftikhar, S., Saboor, A., Khan, A.U. and Khan, M. (2016) Agriculture Land Resources and Food Security Nexus in Punjab, Pakistan: An Empirical Ascertainment. Food and Agricultural Immunology, 27, 52-71. https://doi.org/10.1080/09540105.2015.1079593

[29] Shakun, M.F. (1988) Evolutionary Systems Design, Policy Making under Complexity and Group Decision Support Systems. Holden-Day, Inc., Oakland, CA.

[30] Soros, G. (1998) Fallibility and Reflexivity. In: The Crisis of Global Capitalism, Public Affairs, New York, 3-45.

[31] Simon, H. (1987) Decision Making and Organizational Design. In: Pugh, D.S., Ed., Organizational Theory, Penguin Books, Hammondsworth, Middlesex, 202-223.

[32] Buchanan, J.M. (1999) The Domain of Constitutional Economics. In: The Collected Works of James M. Buchanan, the Logical Foundations of Constitutional Liberty, Vol. 1, Liberty Fund, Indianapolis, IN, 377-395. (Reprinted)

[33] Schumpeter, J.S. (1968) The Scholastic Doctors and the Philosophers of Natural Law. In: History of Economic Analysis, Oxford University Press, New York.

[34] Gruber, T.R. (1993) A Translation Approach to Portable Ontology Specifications. Knowledge Acquisition, 5, 199-200. https://doi.org/10.1006/knac.1993.1008

[35] Newell-McGloughlin, M. (2008) Nutritionally Improved Agricultural Crops. Plant Physiology, 147, 939-953. https://doi.org/10.1104/pp.108.121947

[36] Rucker, R. (1982) Large Cardinals. In: Infinity and the Mind, Bantam Books, New York, 273-286.

[37] Nikaido, H. (1987) Fixed Point Theorems. In: Eatwell, J., Milgate, M. \& Newman, P., Eds., The New Palgrave: General Equilibrium, W. W. Norton, New York, 139144.

[38] Jaiyeoba, H.B., Ndzembanteh, A.N., Ibrahim, T., Yousuf, H.M. and Mory, F.S. (2015) Financing and Developing the Agricultural Sector through Cash Waqf: An Analysis of Cash Waqf Using the Mudarabah Approach. South East Asia Journal of Contemporary Business, Economics and Law, 6. (Online)

[39] AmanahIkhtiar Malaysia (online) visited 2 December 2016. http://wief.org/wp-content/uploads/2012/04/Datuk-Hajah-Zabidah-Ismail.pdf

[40] Grameen Bank Bangladesh online, visited 2 December 2016. http://www.grameen.com/

[41] Dasgupta, S.K., Ahmed, B. and Rahman, K.S., Eds. Annual Report 2015-2016. Bangladesh Academy for Rural Development (BARD) Kotbari, Comilla, Bangladesh.

[42] Choudhury, M.A. and Hossain, M.S. (2006) Development Planning in the Sultanate of Oman. Edwin Mellen Press, Lewiston, New York.

[43] The Economics of Ecosystems and Biodiversity (2015) TEEB for Agriculture and Food: An Interim Report. United Nations Environmental Program, Geneva, Switzerland. 
Submit or recommend next manuscript to SCIRP and we will provide best service for you:

Accepting pre-submission inquiries through Email, Facebook, LinkedIn, Twitter, etc. A wide selection of journals (inclusive of 9 subjects, more than 200 journals)

Providing 24-hour high-quality service

User-friendly online submission system

Fair and swift peer-review system

Efficient typesetting and proofreading procedure

Display of the result of downloads and visits, as well as the number of cited articles Maximum dissemination of your research work

Submit your manuscript at: http://papersubmission.scirp.org/

Or contact tel@scirp.org 